\title{
OPTIMIZATION OF NICKEL (II) AND CHROMIUM (III) REMOVAL FROM CONTAMINATED WATER USING SORGHUM BICOLOR
}

\author{
L. T. Adewoye ${ }^{1}$, S. I. Mustapha ${ }^{2,}{ }^{*}$, A. G. Adeniyi ${ }^{3}$, J. 0. Tijani ${ }^{4}$, M. A. Amoloye ${ }^{5}$ and L. J. Ayinde 6 \\ 1, 2, 3, 5, 6, DEPARTMENT OF CHEMICAL ENGINEERING, UNIVERSITY OF ILORIN, ILORIN, KWARA STATE, NIGERIA

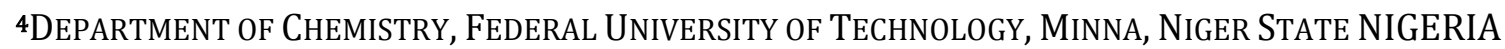 \\ Email addresses: 1 tuntola2002@yahoo.com,2mustapha.si@unilorin.edu.ng,3remson414@yahoo.co.uk, \\ 4jimohtijani@futminna.edu.ng, 5 m.amoloye@yahoo.com,6jide004lawal@gmail.com
}

\begin{abstract}
A central composite design (CCD) under the response surface methodology (RSM)was used to study the effect of three adsorption variables ( $p H$, initial concentration, and adsorbent dosage) in order to determine the optimum process conditions for the adsorptions of $\mathrm{Ni}$ (II) and $\mathrm{Cr}$ (III) onto sulphuric acid modified sorghum bicolor activated carbon (SBAC).This study yielded removal efficiency of $98.89 \%$ for $\mathrm{Ni}$ (II) and $94.27 \%$ for $\mathrm{Cr}$ (III) ion under optimal conditions of $\mathrm{pH}$ (8), initial metal ion concentration (25 $\mathrm{mg} / \mathrm{L})$, adsorbent dosage $(10 \mathrm{mg})$ and $\mathrm{pH}$ (7), initial metal ion concentration $(5 \mathrm{mg} / \mathrm{L})$, dosage (15 mg);respectively. Statistical analysis of variance results showed a good correlation existed between the experimental and predicted data with $R^{2}$ values of 0.99 for $\mathrm{Ni}$ and 0.98 for Cr. The equilibrium data for Ni (II) adsorption was best described using Freundlich model while Langmuir model best fit Cr (III) adsorption. The mechanism of adsorption for both Ni and Cr adsorptions on SBAC followed Pseudo second order kinetic model.
\end{abstract}

Keywords: Sorghum Bicolor, Adsorption, Nickel, Chromium, Isotherm, Kinetics

\section{INTRODUCTION}

The contamination of water sources with potentially toxic elements via natural and anthropogenic activities have become a global phenomenon demanding urgent scientific solutions $[1,2]$. Among the potentially toxic elements, heavy metals such as mercury, cadmium, chromium, nickel, palladium are not easily biodegradable and tend to accumulate in living organisms, causing different health disorders in human depending on the exposure rate and dosage [3]. With increasing stringent regulations placed on the discharge of toxic heavy metals into water bodies, the removal of heavy metal ions from water has become an important subject matter among researchers[4].

Several conventional methods have been used for heavy metals removal from wastewater. These methods include precipitation, electroplating, chemical coagulation, ionexchange, chemical oxidation or reduction, electrochemical treatment, evaporative recovery, filtration and membrane separation [5-11]. However, most of these methods have several shortcomings which include high cost, unavailability, generation of large volumes of secondary waste and poor removal efficiency especially if the heavy metal concentrations are in the range of $1-100 \mathrm{mg} / \mathrm{L}$ [12]. Despite the availability of the above mentioned techniques, adsorption phenomenon is still consider as a logical option and has gained a relatively wider application for the removal of toxic heavy metals from wastewater. This is due to its universal nature, low cost, availability, ease of operation, flexibility, environmental friendliness, high efficiency and effectiveness to mention but a few [13-15]. The efficiency of adsorption depends on many factors such as the surface area, pore size distribution, polarity, and functional groups of the adsorbent.

Several adsorbents commonly used in adsorption process include clay, activated carbon, zeolite and silica gel [4]. The high cost of commercial activated carbon hinders its industrial applications for waste water treatment especially in developing countries. In recent times, the utilization of natural sorbents for the purpose of removing contaminants was reported by many researchers [16-20]. Many agricultural waste materials have been reported in literature for the removal of heavy metals in wastewater, especially nickel and chromium. They include, coconut husk [21], almond shell [22, 23], groundnut hull [24], rice husk [25], wheat bran [26, 27], tea waste [28], peanut hull [29], coffee bean [30], Ficus religiosa leaves [31], maize leaf [32]. In addition, studies have been carried out to ascertain the optimum

* Corresponding author, tel: +234-806-718-6215 
adsorption conditions for efficient removal of these metals from wastewater [3, 33]. An effective system for any process can be established only after optimization of its process parameters. Conventional and classical methods of studying a process involved studying of one factor at a time by keeping other factors fixed. This approach does not depict the combined effect of all the parameters involved in the process. This method is not only tedious but also time consuming [34]. These limitations of a classical method can be effectively conquered by optimizing all the parameters collectively using statistical experimental designs such as response surface approach[35]. These designs reduce the total number of experiments needed to achieve the overall optimization of the process parameters. Response surface methodology (RSM) is a mathematical and statistical technique that was reported to be very useful for analyzing the single and combinatorial effects of several independent variables on the responses [36]. Although several works have been carried out on the utilization of raw agricultural wastes or activated carbon for heavy metal removal from wastewater, to the best of our knowledge, the use of activated carbon prepared from sorghum bicolor stalk for the removal of nickel and chromium have not been reported elsewhere. Therefore, this present study investigated the performance of sorghum bicolor activated with sulphuric acid for the removal of nickel and chromium from aqueous solution using response surface methodology (RSM).

\section{MATERIALS AND METHODS}

\subsection{Materials}

All the chemicals and reagents used were of analytical grade. Distilled water was used for all experimental work including the preparation of metal ion solutions. The desired $\mathrm{pH}$ of the metal ion solutions were adjusted using $0.1 \mathrm{M} \mathrm{NaOH}$ and $0.2 \mathrm{M} \mathrm{H}_{2} \mathrm{SO}_{4}$. The final concentration of metal ions were analysed using Atomic Absorption Spectrophotometer (AAS) (BUCK Scientific ACCUSYS 211).

\subsection{Preparation of Adsorbates}

The solutions of $\mathrm{Cr}$ (III) and $\mathrm{Ni}$ (II) metal ions were prepared from analytical grade of their sulfate salts purchased from Sigma - Aldrich and used without any further purification. Stock $\mathrm{Cr}$ (III) and Ni (II) solutions of $1000 \mathrm{mg} / \mathrm{L}$ concentrations were prepared by dissolving, $3.771 \mathrm{~g}$ of $\mathrm{Cr}_{2}\left(\mathrm{SO}_{4}\right)_{3}$ and $2.637 \mathrm{~g}$ of $\mathrm{NiSO}_{4}$, respectively in $1 \mathrm{~L}$ of distilled water. Thereafter, the stock solutions were further diluted to obtain working solutions of the desired initial concentrations of Nickel (II) and Chromium (III).

\subsection{Preparation of Adsorbent}

Sorghum bicolor stalk used in this study was collected from different locations in Ilorin, Kwara State, Nigeria and a composite sample was formed from it. Prior to use, the collected materials were thoroughly washed with distilled water in order to remove adhering impurities and sun dried for 5 days. The crispy sorghum bicolor stalk was crushed and separated using sieve size of 225 $\mu \mathrm{m}$. The uniform particle size sorghum bicolor stalk was subjected to carbonization process in a muffle furnace at temperature of $400^{\circ} \mathrm{C}$ for $2 \mathrm{hrs}[19]$. $400 \mathrm{~g}$ of calcined sorghum bicolor powder was soaked in excess of $0.2 \mathrm{M}$ $\mathrm{H}_{2} \mathrm{SO}_{4}$ (purity 85\%) solution for $24 \mathrm{hrs}$. This was then filtered through a what man filter paper of $11 \mu \mathrm{m}$ size and rinsed with distilled water to obtain a $\mathrm{pH}$ of 7; it was oven dried at $110^{\circ} \mathrm{C}$ for $3 \mathrm{hrs}$ and finally packaged in an air tight container for further use.

\subsection{Characterization of Sorghum Bicolor Activated Carbon (SBAC)}

The surface area and porosity measurement of the SBAC was carried out using Quanta chrome NOVA 4200e UK, surface area and pore size analyzer. The sample in the form of powder was loaded in a bulb ended quartz tube and heated in the furnace to about $350^{\circ} \mathrm{C}$ for out gassing under the flow of liquid nitrogen for about $8 \mathrm{hrs}$ in order to remove moisture and contaminants. Fourier transform infrared spectroscopy (FT-IR) technique was used to examine the surface functional groups responsible for metal adsorption. The FT-IR analyses before and after metal adsorption were performed on the samples using Perkin - Elmer spectrum with resolution of $4 \mathrm{~cm}^{-1}$ in the range of $4000-500 \mathrm{~cm}^{-1}$.

\subsection{Adsorption Experiments}

Batch adsorption studies were conducted to investigate the effect of contact time, solution $\mathrm{pH}$, initial metal ion concentration, and effect of adsorbent dosage on adsorption of both nickel and chromium ion onto sulphuric acid modified sorghum bicolor.

\subsubsection{Effect of Contact Time}

The effect of contact time was investigated by adding 25 $\mathrm{mL}$ of solution taken into $100 \mathrm{~mL}$ Erlenmeyer flasks containing $5 \mathrm{mg} / \mathrm{L}$ of initial metal concentration and 10 $\mathrm{mg}$ of the SBAC adsorbent at a $\mathrm{pH}$ of 6 . The mixture was shaken constantly using an orbit shaker at $140 \mathrm{rpm}$ speed for 20, 30, 40, 50, 60 and 70 mins each. At the end of each contact time period, the mixture was filtered and the chromium and nickel concentrations in solution were determined using AAS. All the experiments were carried out in duplicate and the mean values considered. 


\subsubsection{Effect of $p H$}

The effect of solution $\mathrm{pH}$ on adsorption of the metals was investigated using $10 \mathrm{mg}$ of the adsorbent added to 25 $\mathrm{mL}$ of the aqueous solution containing $5 \mathrm{mg} / \mathrm{L}$ of initial metal ion concentration. The $\mathrm{pH}$ of the solution was varied between the $\mathrm{pH}$ value of 5 and 9 using either $0.1 \mathrm{M}$ $\mathrm{NaOH}$ or $0.2 \mathrm{M} \mathrm{H}_{2} \mathrm{SO}_{4}$. The mixture was shaken for 30 mins and 20 mins for chromium and nickel respectively, then filtered and the amount of metal ion adsorbed was determined using AAS.

\subsubsection{Effect of Initial Concentration}

In order to investigate the effect of concentration on the adsorption of metal ion, $10 \mathrm{mg}$ of SBAC adsorbent was added to $25 \mathrm{~mL}$ of the metal solutions of different initial concentrations (5-25 mg/L) for both $\mathrm{Cr}$ and $\mathrm{Ni}$ ion. The resultant solution with the adsorbent in the flask was shaken at $140 \mathrm{rpm}$, filtered and the amount of metal ions adsorbed was determined using AAS.

\subsubsection{Effect of Adsorbent Dosage}

Different doses of adsorbents ranging from $10-50 \mathrm{mg}$ were separately mixed with $25 \mathrm{~mL}$ of aqueous solution put into $100 \mathrm{~mL}$ Erlenmeyer flasks containing $5 \mathrm{mg} / \mathrm{L}$ of initial metal ion concentration. The mixture was shaken constantly using an orbit shaker at $140 \mathrm{rpm}$ for both nickel and chromium. The mixture was then filtered and the chromium and nickel concentrations in solution were determined using AAS.

2.6 Design of Experiments and Optimization of Parameters Using Response Surface Methodology

In this study, central composite design (CCD) under the response surface methodology was employed to carry out optimization using desirability (D) function to obtain the optimum conditions to achieve better response (removal efficiency of $\mathrm{Ni}$ and $\mathrm{Cr}$ ). Three important adsorption process parameters such as $\mathrm{pH}$, initial metal ion concentration, and adsorbent dose were selected as variables for designing the experimental matrix. Each numeric factor is varied over 5 levels: plus and minus alpha (axial points), plus and minus 1 (factorial points) and the center - point. For a three-factor scenario where $\mathrm{n}$ is equal to there (3), CCD is characterized by $2 \mathrm{n}$ axial runs ( 6 axial points), $2^{\mathrm{n}}$ factorial runs ( 8 factorial points) and 6 replicates at the center which gives a total of 20 experiments. The levels and ranges of the factors studied are presented in Table 1.

The optimal conditions for the response were determined using the optimal model predictor quadratic equation [33] given as:

$$
Y=b_{o}+\sum b_{i i} A_{i}+\left(\sum b_{i i} A_{i}\right)^{2}+\sum b_{i j} A_{i} A_{j}
$$

In (1), $\mathrm{Y}$ is the predicted response (removal efficiency), bo is the constant coefficients, bii is the quadratic coefficients, bij is the interaction coefficients and $\mathrm{Ai}, \mathrm{Aj}$ are the coded values of the variables considered.

Table 1: Experimental ranges and levels of the factors for the Central Composite Design

\begin{tabular}{|c|c|c|c|c|c|c|c|}
\hline \multirow{2}{*}{$\begin{array}{l}\text { Independent } \\
\text { Variable } \\
\text { (Factors) }\end{array}$} & \multirow{2}{*}{$\begin{array}{c}\text { Coded } \\
\text { Symbol }\end{array}$} & \multirow[b]{2}{*}{ Units } & \multicolumn{5}{|c|}{ Range and Levels } \\
\hline & & & -1 & $-\alpha$ & 0 & $+\alpha$ & +1 \\
\hline $\mathrm{pH}$ & $\mathrm{A}$ & - & 5 & 6 & 7 & 8 & 9 \\
\hline $\begin{array}{l}\text { Initial } \\
\text { Concentration }\end{array}$ & B & $\mathrm{mg} / \mathrm{L}$ & 5 & 10 & 15 & 20 & 25 \\
\hline $\begin{array}{l}\text { Adsorbent } \\
\text { Dosage }\end{array}$ & $\mathrm{C}$ & $\mathrm{mg}$ & 10 & 20 & 30 & 40 & 50 \\
\hline
\end{tabular}

A statistical software (Design expert version 6.0.8, Stat Ease, Inc., Minneapolis, MN 55413, USA) was used for the model fitting and for the evaluation of the statistical significance of the $\mathrm{Ni}$ and $\mathrm{Cr}$ adsorption efficiencies. The removal efficiency of the adsorbents on metal ion adsorption was calculated using Equation 2:

$$
\text { Removal efficiency }(\%)=\frac{\left(C_{o}-C_{e}\right)}{C_{o}} \times 100
$$

Here, $\mathrm{C}_{o}$ and $\mathrm{C}_{\mathrm{e}}(\mathrm{mg} / \mathrm{L})$ are the concentrations of metal ions at initial stage and at equilibrium, respectively.

\subsection{Adsorption Isotherm}

The equilibrium adsorption isotherms were depicted by plotting solid phase concentration $\left(Q_{e}\right)$ against liquid phase concentration $\left(\mathrm{C}_{\mathrm{e}}\right)$ of solute. The adsorption isotherms of the $\mathrm{Ni}$ and $\mathrm{Cr}$ ions onto the adsorbent(SBAC) were determined at $30^{\circ} \mathrm{C}$ in the range of concentrations between 5 and $25 \mathrm{mg} \mathrm{L}^{-1}$, and the obtained optimum parameters for $\mathrm{pH}$, adsorbent dosage and equilibrium time were used to model the adsorption process. The amount of $\mathrm{Ni}$ and $\mathrm{Cr}$ metal ion removed per mass of adsorbent was calculated using the equation 3 :

$$
Q_{e}=\frac{\left(C_{o}-C_{e}\right) V}{m}
$$

Here, $\mathrm{Q}_{\mathrm{e}}\left(\mathrm{mg} \mathrm{g}^{-1}\right)$ is the amount of metal ion adsorbed per unit mass of adsorbent at equilibrium.

\subsection{Adsorption Kinetics}

In order to study the kinetics of the adsorption process, concentration of the $\mathrm{Ni}$ and $\mathrm{Cr}$ was determined at time range of 20 to $70 \mathrm{mins}$. The amount of the metal ion adsorbed at time $t, Q_{t}(\mathrm{mg} / \mathrm{g})$ was calculated using the relationship presented in Equation 4.

$$
Q_{t}=\frac{\left(C_{o}-C_{t}\right) V}{m}
$$

In (4), $C_{o}$ and $C_{t}(m g / L)$ are the liquid-phase concentration of $\mathrm{Ni}$ and $\mathrm{Cr}$ at the initial and any time $\mathrm{t}$, respectively. 


\section{RESULTS AND DISCUSSION}

\subsection{Characterization of Sorghum Bicolor Activated Carbon} (SBAC)

Surface area is one of the most important characteristics of adsorbents. The Brunauer Emmett Teller analysis of SBAC gave BET surface area $\left(294.17 \mathrm{~m}^{2} / \mathrm{g}\right)$, micro-pore surface area (392.4 $\left.\mathrm{m}^{2} / \mathrm{g}\right)$, micro-pore volume (0.1395 $\mathrm{cm}^{3} / \mathrm{g}$ ) as shown in Table 2 . The high value of surface area obtained is an indication that the SBAC may have good metal ion uptake capacity. This can be compared with some commercial activated carbons having surface area of $217 \mathrm{~m}^{2} / \mathrm{g}$ [37] and $336.35 \mathrm{~m}^{2} / \mathrm{g}$ [38]. The adsorbent was found to be mesoporous $(2-50 \mathrm{~nm})$ in nature with the average pore diameter $\mathrm{Dp}$ of $2.53 \mathrm{~nm}$.

\section{Table 2: BET Characterization of the Sorghum Bicolor} Activated Carbon

\begin{tabular}{|c|c|c|c|}
\hline $\begin{array}{c}\text { BET } \\
\text { surface } \\
\text { area, } \mathrm{S}_{\mathrm{BET}} \\
\left(\mathrm{m}^{2} / \mathrm{g}\right)\end{array}$ & $\begin{array}{c}\text { Micropore } \\
\text { surface area, } \\
\mathrm{S}_{\mathrm{mic}} \\
\left(\mathrm{m}^{2} / \mathrm{g}\right)\end{array}$ & $\begin{array}{c}\text { Micropore } \\
\text { volume, } V_{\text {mic }} \\
\left(\mathrm{cm}^{3} / \mathrm{g}\right)\end{array}$ & $\begin{array}{c}\text { Pore } \\
\text { Size, Dp } \\
(\mathrm{nm})\end{array}$ \\
\hline 294.17 & 392.4 & 0.1395 & 2.53 \\
\hline
\end{tabular}

The FT-IR spectra for the SBAC before adsorption as shown in Figure 1displays a number of absorption peaks. The broad peak observed at $3345.65 \mathrm{~cm}^{-1}$ corresponds to $\mathrm{O}-\mathrm{H}$ and $\mathrm{N}-\mathrm{H}$ groups $[4,24]$. A medium peak assigned as alkynes with stretches of $\mathrm{C} \equiv \mathrm{C}$ was found around 2080.02 $\mathrm{cm}^{-1}$. The sharp peak located at $1635.64 \mathrm{~cm}^{-1}$ suggests the characteristic of a typical carbonyl group $(\mathrm{C}=0)$ stretching from tertiary amides. The presence of $\mathrm{O}-\mathrm{H}$, alkynes stretches of $\mathrm{C} \equiv \mathrm{C}$, along with the carbonyl group, confirms the presence of carboxylic acid groups in the adsorbent. The peaks at $1403.20 \mathrm{~cm}^{-1}$ and $1122.83 \mathrm{~cm}^{-1}$ are associated with the $\mathrm{C}-\mathrm{H}$ and $\mathrm{C}-\mathrm{O}$ bonds. The FT-IR spectra of SBAC after adsorption of nickel (II) and chromium (III) are shown in Figures 2 and 3, respectively. The SBAC after adsorption had its $\mathrm{O}-\mathrm{H} / \mathrm{N}-\mathrm{H}$ at broad peak of $3430.11 \mathrm{~cm}^{-1}$ and $3356.74 \mathrm{~cm}^{-1}$ for nickel and chromium, respectively. The $\mathrm{O}-\mathrm{H}, \mathrm{N}-\mathrm{H}$, carbonyl and carboxylic functional groups were found on the SBAC after adsorption for both nickel and chromium with a shift in the bands suggesting their involvement in the metal ion binding. On the whole, the intensities of the band were decreased after the adsorption of the $\mathrm{Ni} / \mathrm{Cr}$ metal ions which probably indicate sorption of $\mathrm{Ni} / \mathrm{Cr}$ metal ions on the pores of SBAC. The numerous functional groups $(\mathrm{O}-\mathrm{H}, \mathrm{N}-\mathrm{H}$, carbonyl and carboxylic groups) present in the SBAC adsorbent are important sites responsible for the adsorption activities of both nickel and chromium from wastewater $[5,24,33,38]$.

\subsection{Effect of Contact Time}

The effect of contact time on the extent of nickel and chromium sorption by SBAC is shown in Figure 4. It was observed that the maximum removal of these metals was achieved within 30 minutes for chromium and 20 minutes for nickel. The result shows that the sorption process was rapid within 20 - 30 minutes due to availability of active adsorption sites and this was followed by progressive drop in metal uptake. Slow pore intra - particle diffusion of the metal ion to the interior of the adsorbent and the electrostatic hindrance caused by already sorbed metal ion accounts for the subsequent slower sorption rate as the contact time increases [24]. Figure 5 also shows that the trend of adsorption was $\mathrm{Cr}$ (III) $>\mathrm{Ni}$ (II). This may be attributed to that fact that ion with smaller ionic radii diffuses faster than ion with larger ionic radii [39].

\subsection{Effect of $\mathrm{pH}$}

The solution $\mathrm{pH}$ is an important parameter in heavy metal adsorption process based on the fact that both the adsorbent surface binding sites and the metal ion chemistry in solution are influenced by the solution $\mathrm{pH}$. At low $\mathrm{pH}$ values, the competition for binding sites between the metal cations and protons possibly is responsible for the reduced uptake capacity of the metal. However, with an increase in $\mathrm{pH}$, the negatively charged adsorbent was expected to attract the positively charged nickel and chromium ions [40]. This electrostatic attraction may possibly be responsible for higher metal uptake at higher $\mathrm{pH}$ than at low $\mathrm{pH}$ value. Hence, the maximum removal of chromium (III) and nickel (II) were achieved at $\mathrm{pH} 7.0$ and 8.0 respectively as shown in Figure 5.

\subsection{Effect of Initial Concentration}

The effect of initial concentration of $\mathrm{Cr}$ (III) and $\mathrm{Ni}$ (II) is illustrated in Figure 6. The removal efficiency of chromium decreased from $98.87 \%$ to $72.23 \%$ with increase in the metal ion concentration. This shows that less number of active site is available at high concentration of metal ions leading to competition between metal ions to adsorb on the active site of the adsorbent. It was observed from Figure 6 that the removal efficiency of nickel increased from $82.57 \%$ to 98.89\% when the initial metal ion concentration increased from $12.5 \mathrm{mg} / \mathrm{L}$ to $25 \mathrm{mg} / \mathrm{L}$. This shows that more molecules of the nickel ions in solution competed for available binding sites of the adsorbent at higher concentrations than at lower concentrations. Similar trends were reported in literature $[33,41]$. 


\subsection{Effect of Adsorbent Dosage}

The removal efficiency of metal ion depends on the type and quantity of the adsorbent. As shown in Figure 7, the removal efficiency of chromium ion increased with increase in adsorbent dosage from $10 \mathrm{mg}$ to $50 \mathrm{mg}$. This increase in metal uptake of chromium with increase in adsorbent dosage was due to the increase in surface area and availability of more number of active sites for the adsorption of $\mathrm{Cr}$ (II). In the case of nickel, the removal efficiency decreased with increase in the adsorbent dosage. The reason for this may be due to aggregation or overlapping of the adsorption sites which could lead to an overall decrease in available binding sites. These findings corroborate with previous studies carried out in similar works $[4,18,21,39]$

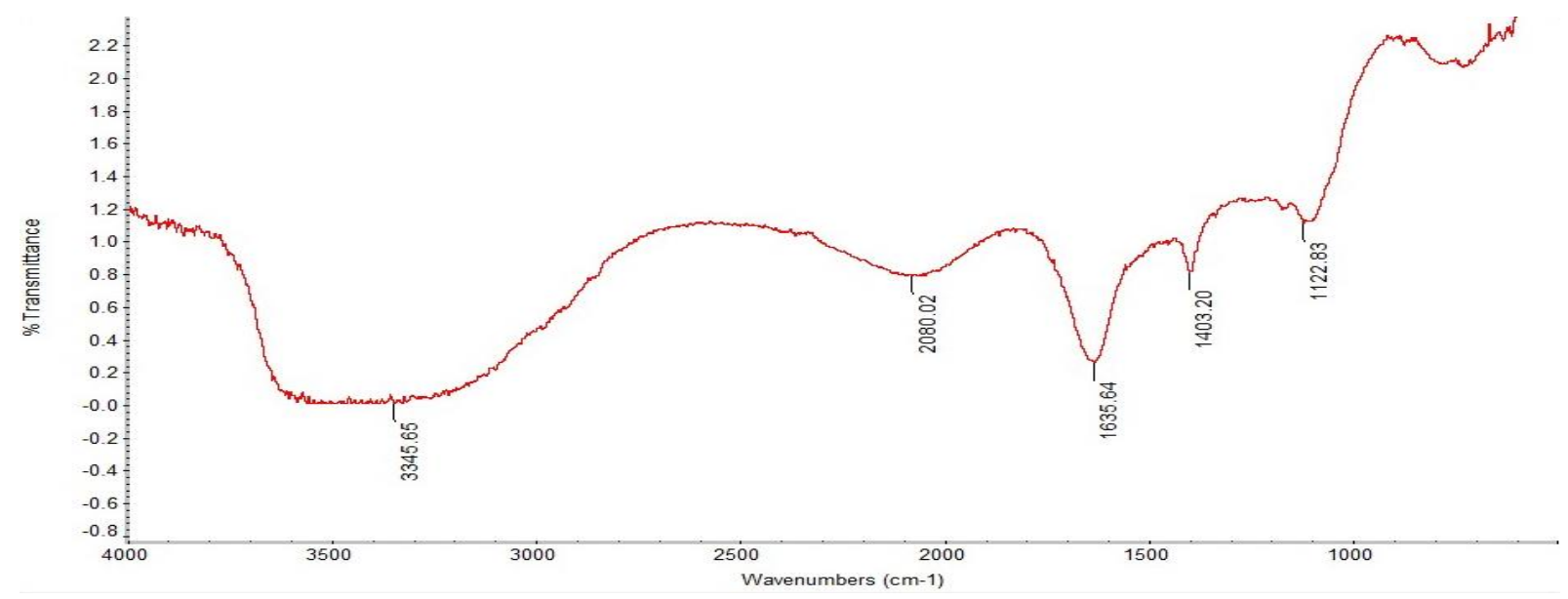

Figure 1: FT-IR for Sorghum Bicolor Activated Carbon (SBAC) before Adsorption

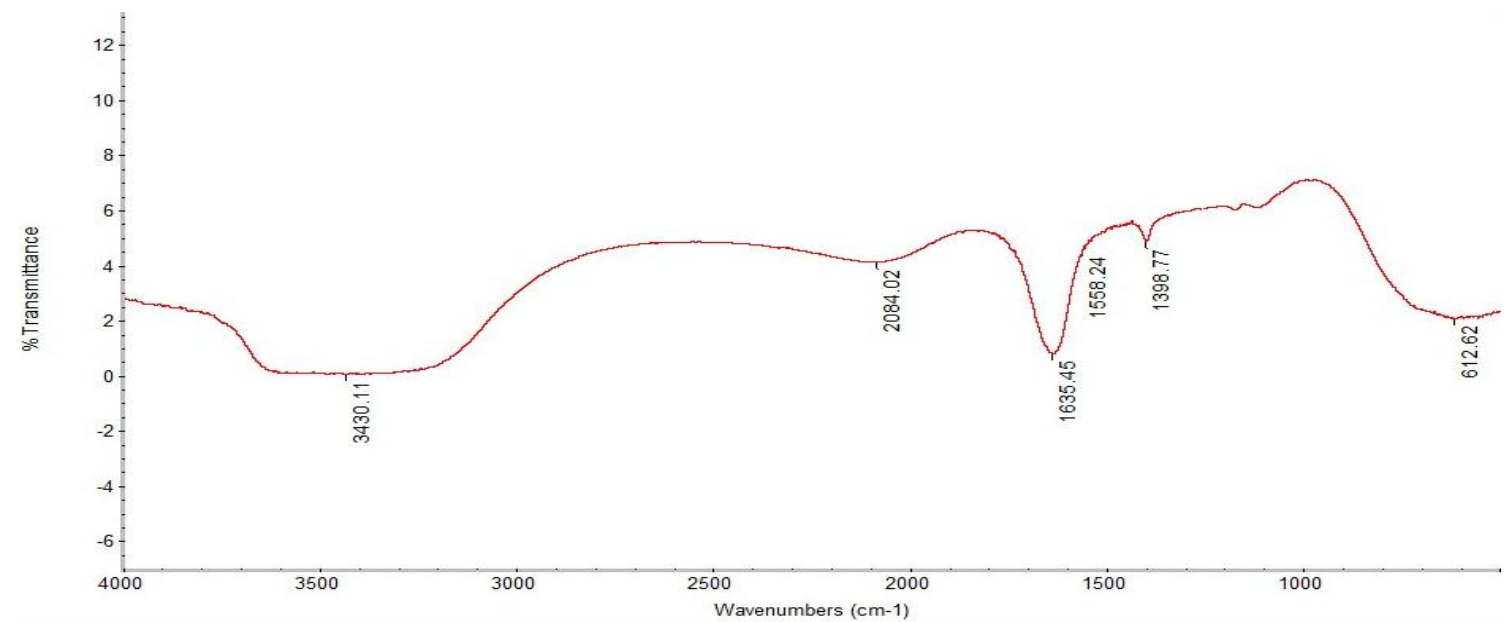

Figure 2: FT-IR for Sorghum Bicolor Activated Carbon (SBAC) After Adsorption of Ni (II)

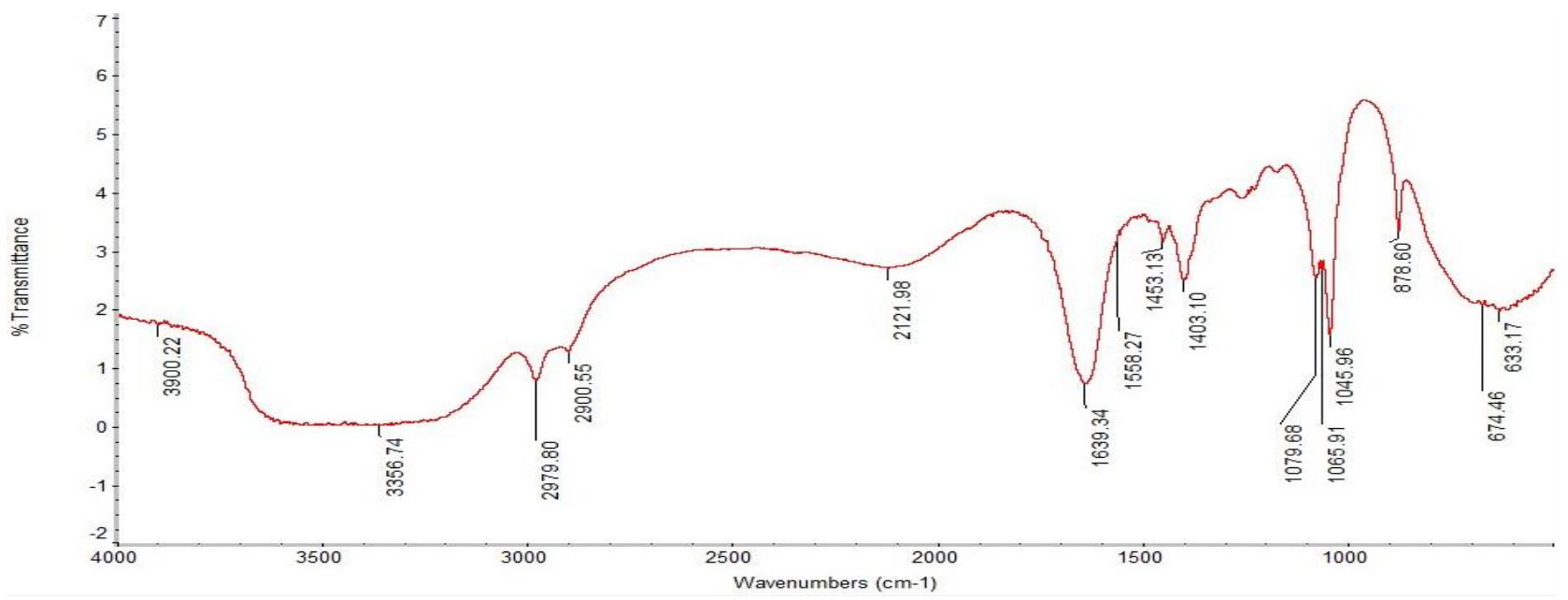

Figure 3: FT-IR for Sorghum Bicolor Activated Carbon (SBAC) After Adsorption of Cr (III) 


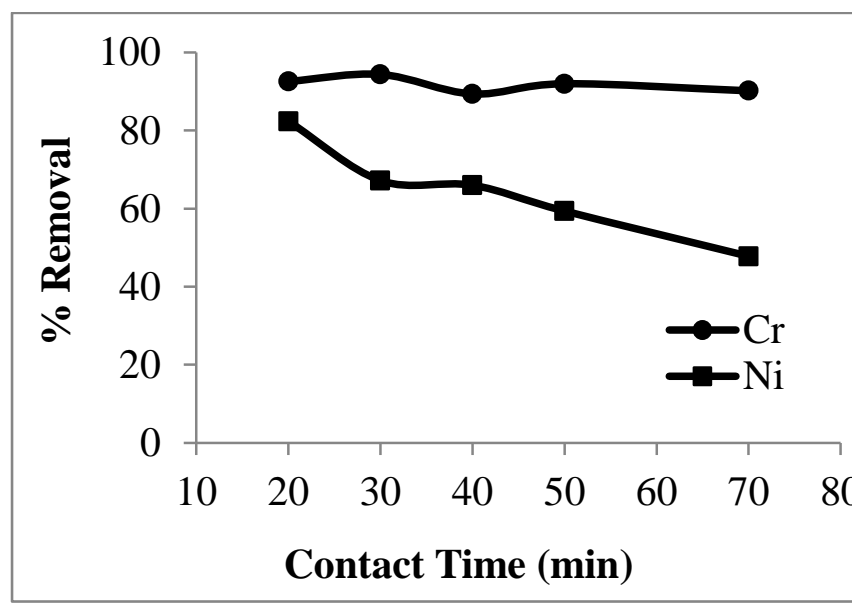

Figure 4: Effect of Contact Time on Adsorption of $\mathrm{Ni} / \mathrm{Cr}$ on SBAC [Ambient Temperature $=30^{\circ} \mathrm{C} ; \mathrm{pH}$ $=6$; Metal ion conc. $=5 \mathrm{mg} / \mathrm{L} ;$ Adsorbent dosage $=10 \mathrm{mg}]$

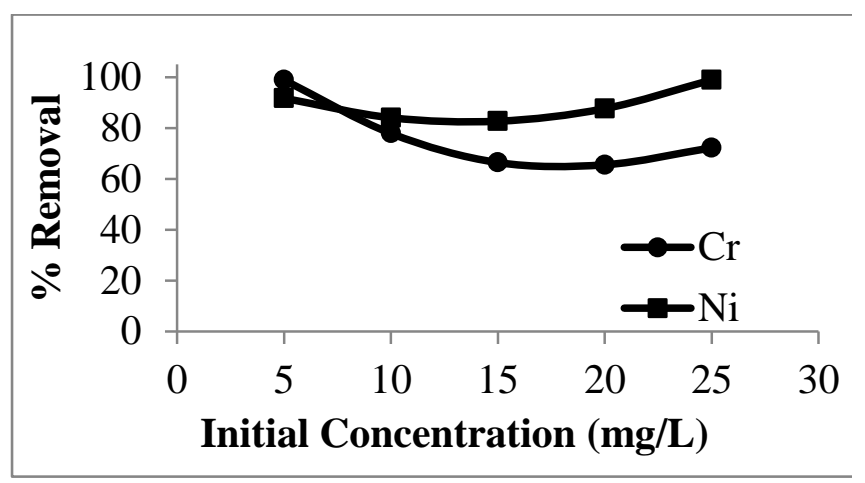

Figure 6: Effect of Initial Metal Ion Concentration on Adsorption of $\mathrm{Ni} / \mathrm{Cr}$ on SBAC [Ambient Temperature $=30^{\circ} \mathrm{C} ; \mathrm{pH}: \mathrm{Cr}=7$ and $\mathrm{Ni}=8$; Adsorbent dosage $=10 \mathrm{mg}$; Contact time: $\mathrm{Cr}=30$ min and $\mathrm{Ni}=20 \mathrm{~min}]$

3.6 Design of Experiments and Optimization of Parameters Using CCD

The experimental design matrix (Table 3) comprising of the adsorption process variables, their ranges and the responses was developed using CCD. The responses are removal efficiency of $\mathrm{Ni}$ (II) and $\mathrm{Cr}$ (III) denoted as $\mathrm{Y}_{\mathrm{Ni}}$ and $\mathrm{Y}_{\mathrm{Cr}}$, respectively. The removal efficiencies of $\mathrm{Ni}$ (II) and $\mathrm{Cr}$ (III) were in the ranges of 10.48 to $97.28 \%$ and 48.6 to $99.8 \%$, respectively.

CCD was used to analyze the experimental data from which polynomial regression equations (quadratic expressions) showing relationship between the adsorption process variables and the responses were developed. The six replicate variables at the center points (run 15 to 20) were used to determine the reproducibility and experimental error of the data. The final empirical model equations with exclusion of insignificant terms for the adsorption of $\mathrm{Ni}$ (II) and $\mathrm{Cr}$ (III) are given as equations (5) and (6) respectively.

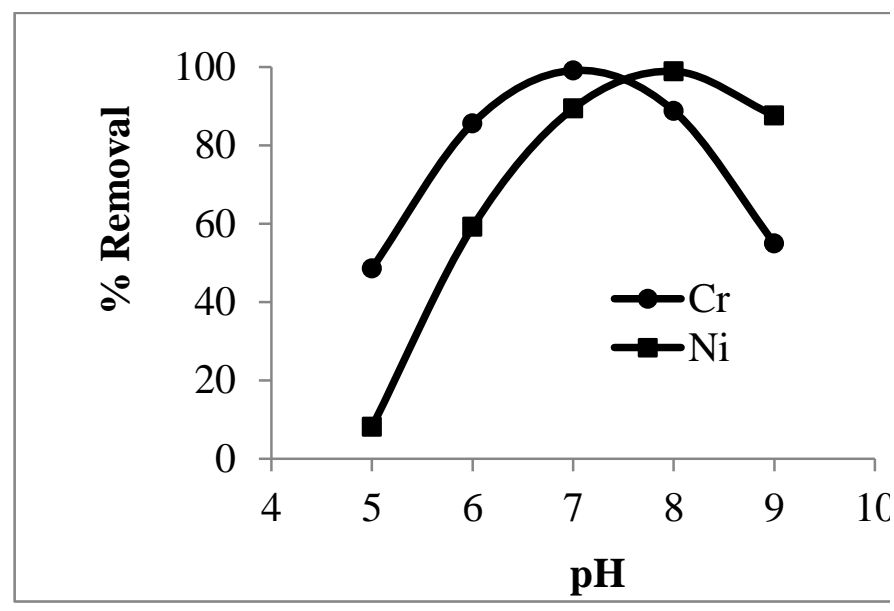

Figure 5: Effect of $p H$ on Adsorption of Ni/Cr on SBAC [Ambient Temperature $=30^{\circ} \mathrm{C}$; Metal ion conc. $=25 \mathrm{mg} / \mathrm{L} ;$ Adsorbent dosage $=10 \mathrm{mg}$; Contact time: $\mathrm{Cr}=30 \mathrm{~min}$ and $\mathrm{Ni}=20 \mathrm{~min}]$

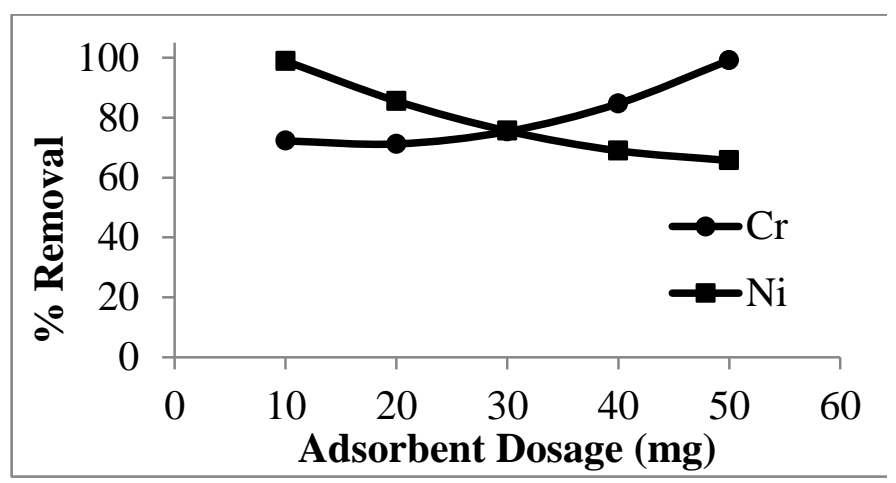

Figure 7: Effect of Adsorbent Dosage on Adsorption of $\mathrm{Ni} / \mathrm{Cr}$ on SBAC [Ambient Temperature $=30^{\circ} \mathrm{C} ; \mathrm{pH}: \mathrm{Cr}=7$ and $\mathrm{Ni}=$ 8; Metal ion conc. $=25 \mathrm{mg} / \mathrm{L}$; Contact time: $\mathrm{Cr}=30 \mathrm{~min}$ and $\mathrm{Ni}=20 \mathrm{~min}]$

$$
\begin{gathered}
\mathrm{Y}_{\mathrm{Ni}}=+74.74+14.82 \mathrm{~A}-2.88 \mathrm{~B}-3.06 \mathrm{C}-46.69 \mathrm{~A}^{2} \\
+14.17 \mathrm{~B}^{2}+6.23 \mathrm{AB}-23.57 \mathrm{AC} \\
-3.81 \mathrm{BC} \\
Y_{C r}=+89.53-9.19 B+9.41 C-49.26 A^{2}+27.32 B^{2} \\
+14.76 C^{2}+4.49 A B+9.84 B C
\end{gathered}
$$

Where; $\mathrm{A}, \mathrm{B}$ and $\mathrm{C}$ represents $\mathrm{pH}$, initial concentration, and adsorbent dosage respectively. The adequacy and significance of the developed quadratic models were evaluated using the F-test of analysis of variance (ANOVA) as shown in Table 4 and Table 5.

From the result (Table 4 and Table 5), the Ni removal model had all the terms to be significant except for $\mathrm{C}^{2}$ found to be insignificant while the terms A and AC were insignificant for $\mathrm{Cr}$ removal model. A good correlation existed between the experimental and predicted data with $\mathrm{R}^{2}$ values of 0.99 for $\mathrm{Ni}$ and 0.98 for $\mathrm{Cr}$. This supports the reliability and validity of the developed models.

The combined interaction effect of the three studied parameters on the absorbance of $\mathrm{Ni}$ and $\mathrm{Cr}$ are shown on 
the three dimensional surface response (Figure 8). Figure 8 (a) and 8 (c) shows the combined effects of $\mathrm{pH}$ and initial concentration on the removal of $\mathrm{Ni}$ and $\mathrm{Cr}$ at constant adsorbent dosage while Figure 8(b) and 8(d) displays the combined effect of adsorbent dosage and initial concentration on the removal of $\mathrm{Ni}$ and $\mathrm{Cr}$ at constant $\mathrm{pH}$. The curvatures obtained for all the response surface plots, clearly indicated that all the studied variables, either individually or by way of interaction contributed to the removal of $\mathrm{Ni}$ and $\mathrm{Cr}$. However the level of contributions to the metal ion may differ.

\subsection{Process Optimization}

The optimization of adsorption of $\mathrm{Ni}$ (II) and $\mathrm{Cr}$ (III) onto SBAC was carried out using Design expert software. The target goal of the optimization process was set to maximize absorbance of both $\mathrm{Ni}$ and $\mathrm{Cr}$ within the experimental range of the studied independent variables. The solution of optimization is usually selected based on the highest desirability or its closeness to unity[42].The optimal conditions obtained for $\mathrm{pH}$, Initial concentration, and adsorbent dosage for $\mathrm{Ni}$ and $\mathrm{Cr}$ were 8, $25 \mathrm{mg} / \mathrm{L}, 10$ $\mathrm{mg}$ and $7,5 \mathrm{mg} / \mathrm{L}, 15 \mathrm{mg}$ respectively. The removal efficiencies of $\mathrm{Ni}$ and $\mathrm{Cr}$ at optimum conditions were found to be $98.89 \%$ and $94.27 \%$ and these values showed a good agreement when compared with those of predicted values with relatively small error of $2.2 \%$ and $1.2 \%$ for $\mathrm{Ni}$ and $\mathrm{Cr}$ respectively.

Table 3: Experimental Design Matrix for Batch Adsorption of Ni and Cr onto SBAC

\begin{tabular}{ccccccccc}
\hline & \multicolumn{3}{c}{ Coded Values } & \multicolumn{3}{c}{ Real Values } & \multicolumn{2}{c}{ Ni removal, } \\
Run & $\mathrm{A}$ & $\mathrm{B}$ & $\mathrm{C}$ & $\mathrm{pH}$ & $\begin{array}{c}\text { Critial Conc. } \\
(\mathrm{mg} / \mathrm{L})\end{array}$ & $\begin{array}{c}\text { Dosage } \\
(\mathrm{mg})\end{array}$ & $\mathrm{Y}_{\mathrm{Ni}}(\%)$ & $\mathrm{Y}_{\mathrm{Cr}}(\%)$ \\
\hline 1 & -1 & -1 & -1 & 5.00 & 5.00 & 10.00 & 18.65 & 99.00 \\
2 & 1 & -1 & -1 & 9.00 & 5.00 & 10.00 & 84.80 & 85.00 \\
3 & -1 & 1 & -1 & 5.00 & 25.00 & 10.00 & 10.48 & 48.60 \\
4 & 1 & 1 & -1 & 9.00 & 25.00 & 10.00 & 97.28 & 58.60 \\
5 & -1 & -1 & 1 & 5.00 & 5.00 & 50.00 & 69.60 & 95.20 \\
6 & 1 & -1 & 1 & 9.00 & 5.00 & 50.00 & 37.20 & 87.60 \\
7 & -1 & 1 & 1 & 5.00 & 25.00 & 50.00 & 41.92 & 90.20 \\
8 & 1 & 1 & 1 & 9.00 & 25.00 & 50.00 & 38.72 & 94.48 \\
9 & -0.5 & 0 & 0 & 6.00 & 15.00 & 30.00 & 53.80 & 79.27 \\
10 & 0.5 & 0 & 0 & 8.00 & 15.00 & 30.00 & 71.07 & 75.79 \\
11 & 0 & -0.5 & 0 & 7.00 & 10.00 & 30.00 & 80.25 & 99.90 \\
12 & 0 & 0.5 & 0 & 7.00 & 20.00 & 30.00 & 75.05 & 93.45 \\
13 & 0 & 0 & -0.5 & 7.00 & 15.00 & 20.00 & 78.27 & 89.87 \\
14 & 0 & 0 & 0.5 & 7.00 & 15.00 & 40.00 & 73.73 & 97.20 \\
15 & 0 & 0 & 0 & 7.00 & 15.00 & 30.00 & 76.40 & 90.13 \\
16 & 0 & 0 & 0 & 7.00 & 15.00 & 30.00 & 75.40 & 87.87 \\
17 & 0 & 0 & 0 & 7.00 & 15.00 & 30.00 & 75.93 & 89.33 \\
18 & 0 & 0 & 0 & 7.00 & 15.00 & 30.00 & 75.93 & 89.97 \\
19 & 0 & 0 & 0 & 7.00 & 15.00 & 30.00 & 74.00 & 90.13 \\
20 & 0 & 0 & 0 & 7.00 & 15.00 & 30.00 & 74.27 & 88.07 \\
\hline
\end{tabular}

Table 4: ANOVA for Response Surface Quadratic Model for Ni Removal

\begin{tabular}{cccccc}
\hline Source & Sum of Squares & Degree of Freedom & Mean Square & F-Value & Prob $>$ F \\
\hline Model & 9923.82 & 9 & 1102.65 & 431.50 & $<0.0001$ \\
A & 1867.32 & 1 & 1867.32 & 730.73 & $<0.0001$ \\
B & 70.33 & 1 & 70.33 & 27.52 & 0.0004 \\
C & 79.77 & 1 & 79.77 & 31.22 & 0.0002 \\
A $^{2}$ & 406.82 & 1 & 406.82 & 159.20 & $<0.0001$ \\
B $^{2}$ & 37.47 & 1 & 37.47 & 14.66 & 0.0033 \\
C $^{2}$ & 10.70 & 1 & 10.70 & 4.19 & 0.0680 \\
AB & 310.63 & 1 & 310.63 & 121.56 & $<0.0001$ \\
AC & 4443.89 & 1 & 4443.89 & 1739.01 & $<0.0001$ \\
BC & 116.05 & 1 & 116.05 & 45.41 & $<0.0001$ \\
Residual & 25.55 & 10 & 2.56 & - & - \\
\hline
\end{tabular}


Optimization of Nickel (II) ANd Chromium (III) Removal from Contaminated Water using Sorghum Bicolor, L. T. Adewoye, et al

Table 5: ANOVA for Response Surface Quadratic Model for Cr Removal

\begin{tabular}{cccccc}
\hline Source & Sum of Squares & Degree of Freedom & Mean Square & F-Value & Prob $>$ F \\
\hline Model & 3064.83 & 9 & 340.54 & 99.62 & $<0.0001$ \\
A & 9.66 & 1 & 9.66 & 2.83 & 0.1237 \\
B & 718.43 & 1 & 718.43 & 210.18 & $<0.0001$ \\
C & 751.91 & 1 & 751.91 & 219.97 & $<0.0001$ \\
$A^{2}$ & 452.85 & 1 & 452.85 & 132.48 & $<0.0001$ \\
B $^{2}$ & 139.29 & 1 & 139.29 & 40.75 & $<0.0001$ \\
C $^{2}$ & 40.66 & 1 & 40.66 & 11.89 & 0.0062 \\
AB & 160.92 & 1 & 160.92 & 47.08 & $<0.0001$ \\
AC & 0.058 & 1 & 0.058 & 0.017 & 0.8991 \\
BC & 773.82 & 1 & 773.82 & 226.38 & $<0.0001$ \\
Residual & 34.18 & 10 & 3.42 & - & - \\
\hline
\end{tabular}

a.

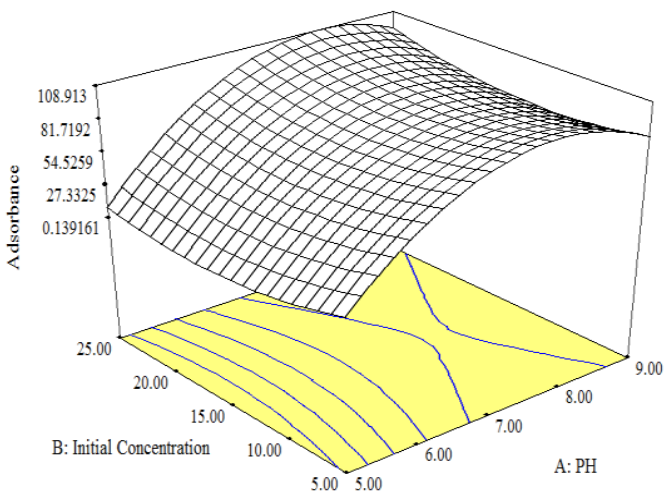

c.

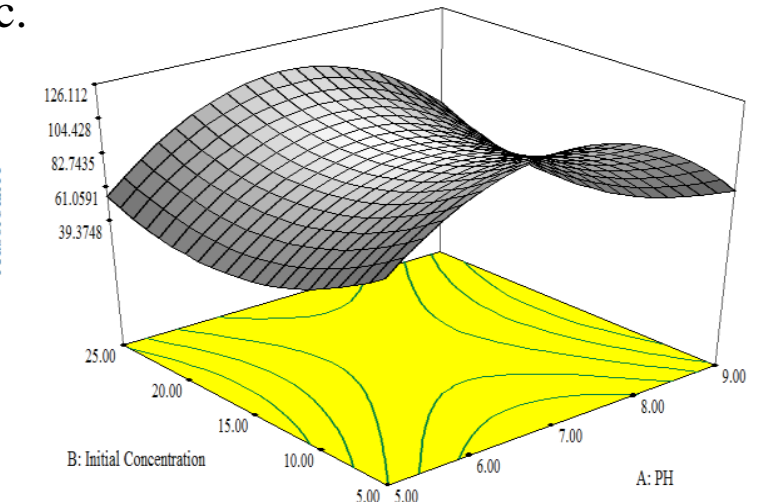

b.

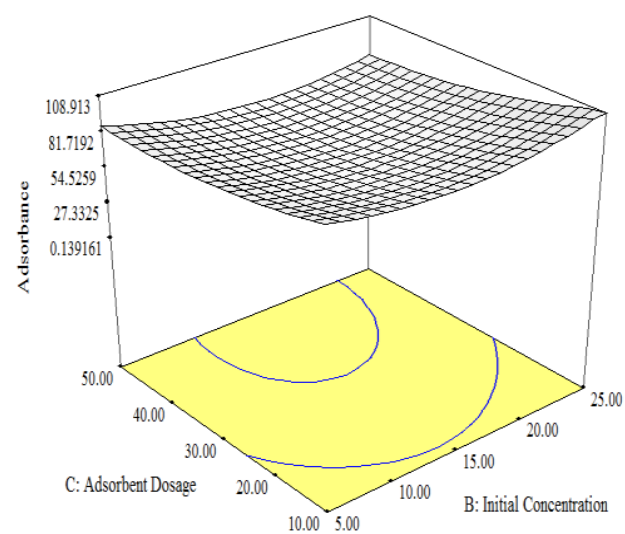

d.

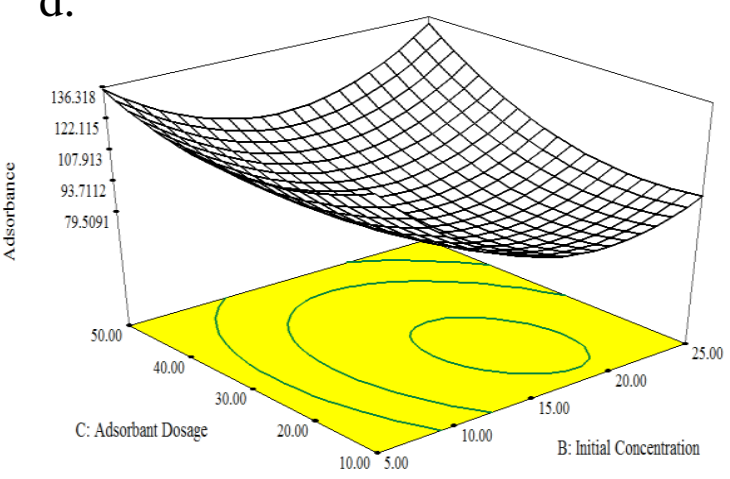

Figure 8: Three-dimensional response surface plots: (a) effect of initial concentration and pH on Ni removal by $S B A C$, (b) effect of adsorbent dosage and initial concentration on Ni removal by SBAC, (c) effect of initial concentration and $p H$ on Cr removal by SBAC, (d) effect of adsorbent dosage and initial concentration on $C r$ removal by $S B A C$

\subsection{Adsorption Isotherm}

The equilibrium characteristic of the adsorption in this study was described using Langmuir and Freundlich isotherm models.

The linearize form of the Langmuir isotherm model [43] is given as:

$$
\frac{C_{e}}{Q_{e}}=\frac{1}{b Q_{m}}+\frac{C_{e}}{Q_{m}}
$$

Where; $\mathrm{C}_{\mathrm{e}}(\mathrm{mg} / \mathrm{L})$ is the equilibrium concentration of adsorbate in solution after adsorption, $Q_{e}(\mathrm{mg} / \mathrm{L})$ is the amount of metal ion adsorbed at equilibrium, $Q_{\mathrm{m}}(\mathrm{mg} / \mathrm{g})$ is the maximum monolayer adsorbent capacity and $b$ ( $\mathrm{L} / \mathrm{mg}$ ) is the Langmuir constant. The Langmuir isotherm was obtained by plotting $\mathrm{C}_{\mathrm{e}} / \mathrm{Q}_{\mathrm{e}}$ against $\mathrm{C}_{\mathrm{e}}$ and straight lines as shown in Figure 9 were fitted to the plots. 
The linearize form of the Freundlich model [44] is given as:

$$
\ln Q_{e}=\ln k_{f}+(1 / n) \ln C_{e}
$$

Where; $\mathrm{k}_{\mathrm{f}}(\mathrm{L} / \mathrm{g})$ and $\mathrm{n}$ are the Freundlich isotherm constants which show the capacity and intensity of the adsorption, respectively. The Freundlich isotherm was obtained by plotting $\mathrm{Q}_{\mathrm{e}}$ versus $\mathrm{C}_{\mathrm{e}}$ on a logarithmic scale and straight lines as shown in Figure 10 were fitted by regression. Langmuir isotherm plot gave a better fitted curve for chromium adsorption data than for nickel (Figure 9). The poor fitted curves for nickel as shown in Figure 9 revealed that the adsorption process did not follow the model. The values of the Langmuir and Freundlich model parameters evaluated from the slope and intercept of lines in Figure 9 and Figure 10 along with the correlation coefficients $\left(\mathrm{R}^{2}\right)$ are presented in Table 6.

From the results (Table 6), the equilibrium data for the sorption of nickel metal ion conformed to the Freundlich model with a high correlation coefficient $\left(\mathrm{R}^{2}=0.977\right)$. On the other hand, the Langmuir model was found more suitable for the sorption of chromium ion with $\mathrm{R}^{2}=0.98$. The parameter $1 / \mathrm{h}$ gives information on adsorption intensity or surface heterogeneity with values between 0 and 1 becoming more heterogeneous as the value gets closer to zero [36]. The $1 / \mathrm{n}$ values obtained for the two adsorbates showed that the adsorption surface of SBAC was heterogeneous in nature. The $\mathrm{k}_{\mathrm{f}}$ values showed that SBAC adsorption capacity for $\mathrm{Cr}(18.07 \mathrm{mg} / \mathrm{g})$ was slightly higher than that of $\mathrm{Ni}(17.39 \mathrm{mg} / \mathrm{g})$. This conformed to the observation reported by previous author [21] for the removal of nickel and chromium ions using modified coconut husk. The monolayer adsorption capacity $\left(Q_{m}\right)$ values of $47.62 \mathrm{mg} / \mathrm{g}$ for nickel and 25.64 $\mathrm{mg} / \mathrm{g}$ for chromium observed in this study compared well with some other adsorbents reported from literature as shown in Table 7.

\subsection{Adsorption Kinetics}

In this study, Pseudo first order and Pseudo second order kinetic models were used to evaluate the mechanism of adsorption. The linearize form of pseudo first order model Equation [53] is given as:

$$
\log \left(Q_{e}-Q_{t}\right)=\log Q_{e}-\frac{k_{1}}{2.303} t
$$

Where; $\mathrm{k}_{1}\left(\mathrm{~min}^{-1}\right)$ is the pseudo - first order rate constant, $Q_{\mathrm{e}}(\mathrm{mg} / \mathrm{g})$ and $\mathrm{Q}_{\mathrm{t}}(\mathrm{mg} / \mathrm{g})$ are the metal ion adsorbed at equilibrium and at time $\mathrm{t}$ (mins) respectively. Plots of $\log \left(\mathrm{Q}_{\mathrm{e}}-\mathrm{Q}_{\mathrm{t}}\right)$ against $(\mathrm{t})$ gave poor fitted curves (Figure 11) indicating the adsorption process was not describe by pseudo - first order kinetic model.

Table 6: Langmuir and Freundlich Isotherms for Ni (II) and Cr (III) Adsorption on SBAC

\begin{tabular}{ccccccc}
\hline Metal & \multicolumn{3}{c}{ Langmuir } & \multicolumn{3}{c}{ Freundlich } \\
\cline { 2 - 6 } & $\mathrm{Q}_{\mathrm{m}}(\mathrm{mg} / \mathrm{g})$ & $\mathrm{b}(\mathrm{L} / \mathrm{mg})$ & $\mathrm{R}^{2}$ & $\mathrm{k}_{\mathrm{f}}$ & $1 / \mathrm{n}$ & $\mathrm{R}^{2}$ \\
\hline $\mathrm{Ni}(\mathrm{II})$ & 47.62 & 0.62 & 0.896 & 17.39 & 0.524 & 0.977 \\
$\mathrm{Cr}(\mathrm{III})$ & 25.64 & 2.60 & 0.980 & 18.07 & 0.147 & 0.935 \\
\hline
\end{tabular}

Table 7: Removal Efficiency of Different Adsorbents for Ni (II) and Cr (III) Adsorption

\begin{tabular}{cccc}
\hline Adsorbates & Adsorbents & $Q_{\mathrm{m}}(\mathrm{mg} / \mathrm{g})$ & References \\
\hline $\mathrm{Ni}$ (II) & SBAC & 47.62 & This work \\
$\mathrm{Cr}$ (III) & SBAC & 25.64 & This work \\
$\mathrm{Ni}$ (II) & Powder of Mosambi fruit peelings & 29.41 & {$[45]$} \\
$\mathrm{Cr}$ (III) & Cocoa shell & 2.52 & {$[46]$} \\
$\mathrm{Ni}$ (II) & Almond husk activated carbon & 37.18 & {$[47]$} \\
$\mathrm{Cr}$ (III) & Bentonite & 4.29 & {$[48]$} \\
$\mathrm{Ni}$ (II) & Loofa sponge & 6.1 & {$[49]$} \\
$\mathrm{Cr}$ (III) & Loofa sponge & 4.97 & {$[50]$} \\
$\mathrm{Ni}$ (II) & Multi - walled carbon nanotubes & 18.08 & {$[51]$} \\
$\mathrm{Ni}$ (II) & Hazelnet shell & 10.11 & {$[52]$} \\
\hline
\end{tabular}

Table 8: Pseudo - First order and Pseudo - second order kinetics for Ni (II) and Cr (III) Adsorption on SBAC

\begin{tabular}{ccccccc}
\hline Metal & \multicolumn{2}{c}{ Pseudo - first order parameters } & \multicolumn{3}{c}{ Pseudo - second order parameters } \\
\cline { 2 - 6 } & $\mathrm{Q}_{\mathrm{e}}(\mathrm{mg} / \mathrm{g})$ & $\mathrm{k}_{1}\left(\mathrm{~min}^{-1}\right)$ & $\mathrm{R}^{2}$ & $\mathrm{Q}_{\mathrm{e}}(\mathrm{mg} / \mathrm{g})$ & $\mathrm{k}_{2}(\mathrm{~g} / \mathrm{mg} \mathrm{min})$ & $\mathrm{R}^{2}$ \\
\hline $\mathrm{Ni}$ (II) & 1.824 & 0.018 & 0.84 & 5.181 & 0.016 & 0.98 \\
$\mathrm{Cr}$ (III) & 0.689 & 0.007 & 0.33 & 11.236 & 0.087 & 0.99 \\
\hline
\end{tabular}


The values of $\mathrm{k}_{1}$ and $\mathrm{Q}_{\mathrm{e}}$ determined from the slope and intercept of lines in Figure 11 were presented in Table 8. The linearize form of pseudo second order model [54] is given as:

$$
\frac{t}{Q_{t}}=\frac{1}{k_{2} Q_{e}^{2}}+\frac{1}{Q_{e}} t
$$

Where; $\mathrm{k}_{2}$ (g/mg min) is the pseudo - second order rate constant, $\mathrm{Q}_{\mathrm{e}}(\mathrm{mg} / \mathrm{g})$ and $\mathrm{Q}_{\mathrm{t}}(\mathrm{mg} / \mathrm{g})$ are the metal ion adsorption capacity at equilibrium and at any time $t$ (min) respectively. Plots of $t / Q_{t}$ against time $(t)$ gave very good fitted curves as shown in Figure 12. The parameters generated from the plots of pseudo second order kinetic model for the adsorption of $\mathrm{Ni}$ and $\mathrm{Cr}$ on SBAC are tabulated in Table 8.

The values of the parameters as presented in Table 8show clearly that pseudo second order kinetic model described well the adsorption process for both nickel and chromium with high regression coefficient $\left(\mathrm{R}^{2}\right)$ values of 0.98 and 0.99 , respectively. The equilibrium constant $\left(\mathrm{k}_{2}\right)$ of the second order kinetic was found to be 0.016 and 0.087 for $\mathrm{Ni}$ and $\mathrm{Cr}$, respectively. This suggest that adsorption of nickel and chromium onto SBAC was based on chemical reactionbetween the metals and active site of the adsorbent. The FTIR spectra (Figure 1 3) also supported this argument. In addittion to the high $\mathrm{R}^{2}$ values, the values of equilibrium capacities for second order kinetic model as shown in Table 8 were in close

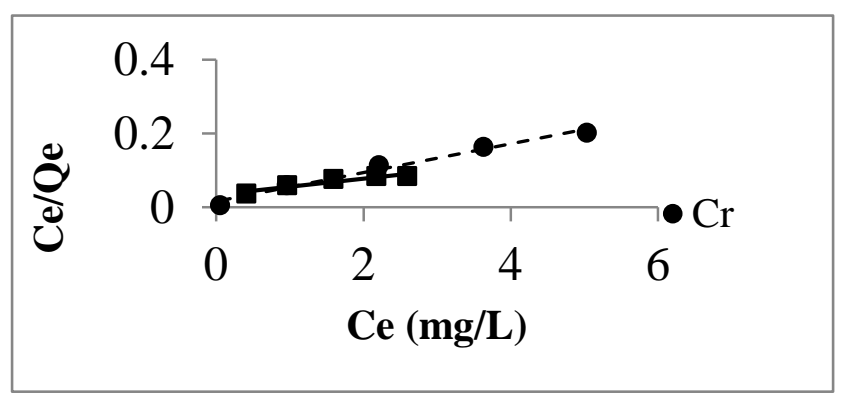

Figure 9: Langmuir adsorption isotherm for $\mathrm{Cr}$ (III) and Ni (II)

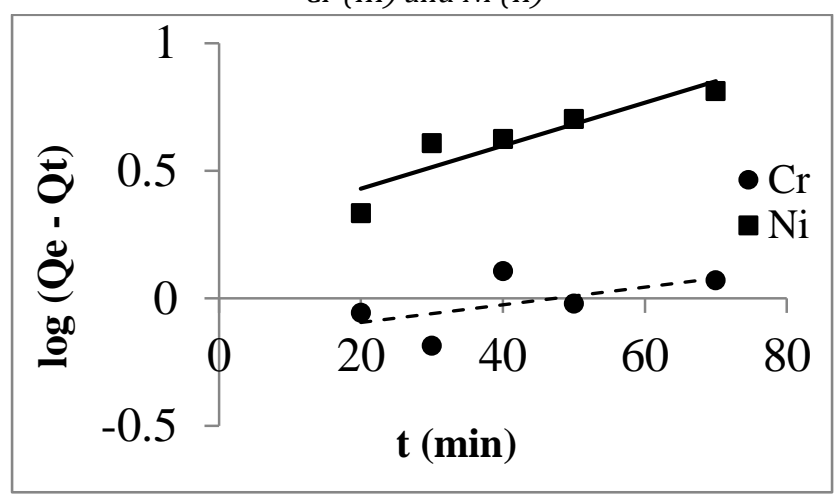

Figure 11: Pseudo - first order kinetic model for sorption of Cr (III) and $\mathrm{Ni}$ (II) agreement to the experimental equilibrium adsorption capacity $(12.45 \mathrm{mg} / \mathrm{g})$.

\section{CONCLUSIONS}

The potentials of sulphuric acid activated sorghum bicolor as one of the possible low cost adsorbent for the removal of $\mathrm{Ni}$ (II) and $\mathrm{Cr}$ (III) from contaminated water was evaluated. The CCD in RSM was successfully used to determine the optimum process conditions for the removal efficiency of $\mathrm{Ni}$ (II) and $\mathrm{Cr}$ (III). The optimal conditions to achieve effective removal of Ni (II) were contact time of 20 mins, $\mathrm{pH}$ of 8 , initial metal ion concentration of $25 \mathrm{mg} / \mathrm{L}$, and adsorbent dosage of 10 mg while that of $\mathrm{Cr}$ (III) were $\mathrm{pH}$ of 7 , initial metal ion concentration of $5 \mathrm{mg} / \mathrm{L}$, adsorbent dosage of $15 \mathrm{mg}$ and contact time of 30 mins.

The adsorption of $\mathrm{Ni}$ (II) and $\mathrm{Cr}$ (III) from aqueous solution was dependent on contact time, solution $\mathrm{pH}$, initial ion concentration and adsorbent dosage. The equilibrium data for Ni (II) adsorption best fit Freundlich model; on the other hand $\mathrm{Cr}$ (III) adsorption was best described using Langmuir model. The mechanism of adsorption for both $\mathrm{Ni}$ and $\mathrm{Cr}$ adsorptions on SBAC obeyed Pseudo second order kinetic model than Pseudo - first order model. The results show that the prepared SBAC is a promising adsorbent for the removal of nickel and chromium ions from contaminated water.

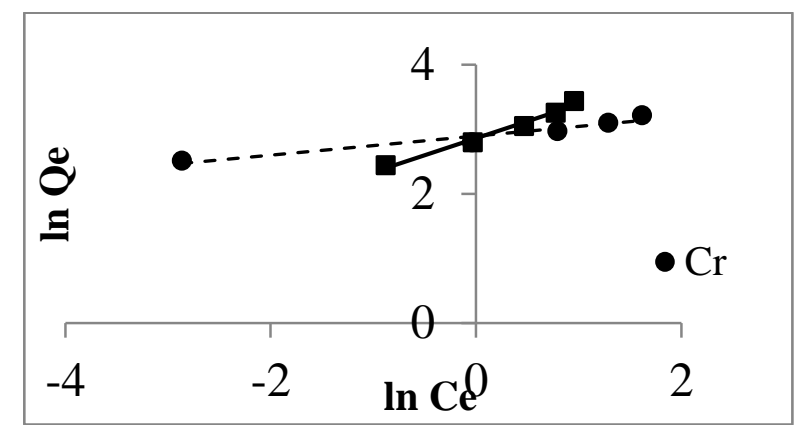

Figure10: Freundlich adsorption isotherm for Cr (III) and Ni (II)

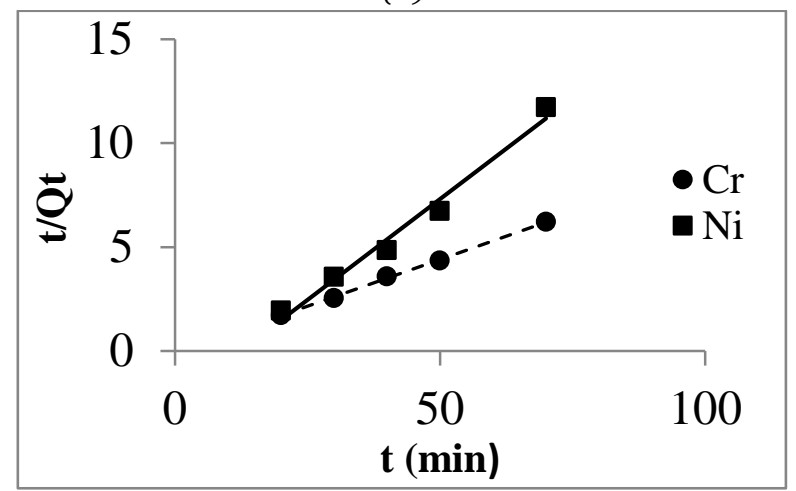

Figure 12: Pseudo - second order kinetic model for sorption of Cr (III) and Ni (II) 


\section{REFERENCES}

[1] Imaga, C. and Abia, A. A. "Kinetics and Mechanisms of Cadmium (II) Ion Sorption Using Carbonized and Modified Sorghum (Sorghum Bicolor) Hull of Two Pore Sizes (CMSH $150 \mu \mathrm{m}$ and 250 $\mu \mathrm{m}) "$, International Journal of Chemical and Process Engineering Research, Vol. 2, Number 4, pp 44-58, 2015.

[2] Izinyon, O. C., Nwosu, O. E., Akhigbe, L. O. and Ilaboya, I. R. "Performance Evaluation of Fe (III) Adsorption Onto Brewers' Spent Grain", Nigerian Journal of Technology, Vol. 35, Number 4, pp 970978, 2016.

[3] Garba, Z. N., Bello, I., Galadima, A. and Lawal, A. Y. "Optimization of adsorption conditions using central composite design for the removal of copper (II) and lead (II) by defatted papaya seed", International Journal of Modern Science, Vol. 2, Number 1, , pp 20 - 28, 2016.

[4] Krishnie, M., Ruella, S., Evans, T. M., Maurice, S. 0. and Aoyi, 0. "Removal of nickel from wastewater using an agricultural adsorbent", Water SA, Vol. 37, Number 1, pp 41-46, 2011.

[5] Duran, C., Ozdes, D., Gundogdu, A. and Senturk, H. B. "Kinetics and Isotherm Analysis of Basic Dyes Adsorption onto Almond Shell (Prunus dulcis) as a Low Cost Adsorbent", Journal of Chemical \& Engineering Data, Vol. 56, Number 5, pp 2136-2147, 2011.

[6] Salman, J. M., Njoku, V. O. and Hameed, B. H. "Adsorption of pesticides from aqueous solution onto banana stalk activated carbon", Chemical Engineering Journal, Vol. 174, Number 1, pp 41-48, 2011.

[7] Ahmaruzzaman, M. and Gayatri, S. L. "Activated tea waste as a potential low-cost adsorbent for the removal of p-nitrophenol from wastewater", Journal of Chemical \& Engineering Data, Vol. 55, Number 11, pp 4614-4623, 2010.

[8] Salman, J. M. and Hameed, B. H. "Effect of preparation conditions of oil palm fronds activated carbon on adsorption of bentazon from aqueous solutions", J Hazard Mater., Vol. 175, Number 1-3, 2010, pp 133-137.

[9] Altinisik, A., Gur, E. and Seki, Y. "A natural sorbent, Luffa cylindrica for the removal of a model basic dye", J Hazard Mater., Vol. 179, Number 1-3, pp 658664,2010

[10] Ahmed, M. J., Ahmaruzzaman, M. and Reza, R. A. "Lignocellulosic-derived modified agricultural waste: development, characterisation and implementation in sequestering pyridine from aqueous solutions", $J$
Colloid Interface Sci., Vol. 428, Number 1, pp 222234, 2014

[11] Reddy, M. C., Sivaramakrishna, L. and Reddy, A. V. "The use of an agricultural waste material, Jujuba seeds for the removal of anionic dye (Congo red) from aqueous medium", J Hazard Mater., Vol. 203204, Number 1, pp 118-127, 2012.

[12] Igunnu, E. T. and Chen, G. Z. "Produced water treatment technologies", International Journal of Low-Carbon Technologies, Vol. 9, Number 3, pp 157177,2014

[13] Ali, I., Asim, M. and Khan, T. A. "Low cost adsorbents for the removal of organic pollutants from wastewater", J Environ Manage. Vol. 113, Number 1, pp 170-183. , 2012.

[14] Ahmad, M. A. and Alrozi, R. "Removal of malachite green dye from aqueous solution using rambutan peel-based activated carbon: Equilibrium, kinetic and thermodynamic studies", Chemical Engineering Journal, Vol. 171, Number 2, pp 510516, 2011.

[15] Angin, D. "Utilization of activated carbon produced from fruit juice industry solid waste for the adsorption of Yellow 18 from aqueous solutions", Bioresour Technol., Vol. 168, Number 1, pp 259-266, 2014.

[16] Yahya, M. A. Al-Qodah, Z. and Ngah, C. W. Z. "Agricultural bio-waste materials as potential sustainable precursors used for activated carbon production: A review", Renewable and Sustainable Energy Reviews, Vol. 46, Number 1, pp 218-235, 2015.

[17] Agarry, S. E. and Owabor, C. N. "Evaluation of the Adsorption Potential Of Rubber (Hevea Brasiliensis) Seed Pericarp-Activated Carbon In Abattoir Wastewater Treatment and in the Removal of Iron (III) Ions from Aqueous Solution", Nigerian Journal of Technology, Vol. 31, Number 3, pp 346-358, 2012.

[18] Nethaji, S. and Sivasamy, A. "Removal of hexavalent chromium from aqueous solution using activated carbon prepared from walnut shell biomass through alkali impregnation processes", Clean Technologies and Environmental Policy, Vol. 16, Number 2, 2014, pp 361-368, 2014.

[19] Raju, A. I., Kumari, S. R., Satya, V., Rao, P. J. and Bai, T. M. "Biosorption performance of Albezia lebbeck pods powder for the removal of lead: Application of statistical method.", International Journal of Modern Engineering Research Vol. 2, Number 3, 2012, pp 1297-1305.

[20] Sarma, P., Kumar, R. and Pakshirajan, K. "Batch and Continuous Removal of Copper and Lead from Aqueous Solution using Cheaply Available Agricultural Waste Materials", Int. J. Environ. Res, Vol. 9, Number 2, pp 635-648, 2015. 
[21] Olayinka, O. K., Oyedeji, O. A. and Oyeyiola, A. "Removal of chromium and nickel ions from aqueous solution by adsorption on modified coconut husk", African Journal of Environmental Science and Technology, Vol. 3, Number 10, pp 286 - 293. , 2009.

[22] Demirbas, E., Kobya, M., Senturk, E. and Ozkan, T. "Adsorption kinetics for the removal of chromium (VI) from aqueous solutions on the activated carbons prepared from agricultural wastes", Water Sa, Vol. 30, Number 4, 2004, pp 533-539.

[23] Pehlivan, E. and Altun, T. "Biosorption of chromium (VI) ion from aqueous solutions using walnut, hazelnut and almond shell", Journal of Hazardous Materials, Vol. 155, Number 1, pp 378384,2008 .

[24] Qaiser, S., Saleemi, A. R. and Umar, M. "Biosorption of lead(II) and chromium(VI) on groundnut hull: Equilibrium, kinetics and thermodynamics study", Electronic Journal of Biotechnology, Vol. 12, Number 4, pp 3-4, 2009.

[25] Vieira, M., De Almeida Neto, A., Silva, M., Nóbrega, C. and Melo Filho, A. "Characterization and use of in natura and calcined rice husks for biosorption of heavy metals ions from aqueous effluents", Brazilian Journal of Chemical Engineering, Vol. 29, Number 3, 2012, pp 619-634, 2012.

[26] Nameni, M., Moghadam, M. A. and Arami, M. "Adsorption of hexavalent chromium from aqueous solutions by wheat bran", International Journal of Environmental Science \& Technology, Vol. 5, Number 2, pp 161-168, 2008.

[27] Altun, T. and Pehlivan, E. "Removal of Cr (VI) from aqueous solutions by modified walnut shells", Food Chemistry, Vol. 132, Number 2, pp 693-700, 2012.

[28] Amarasinghe, B. and Williams, R. "Tea waste as a low cost adsorbent for the removal of $\mathrm{Cu}$ and $\mathrm{Pb}$ from wastewater", Chemical Engineering Journal, Vol. 132, Number 1, pp 299-309, 2007.

[29] Brown, P., Jefcoat, I. A., Parrish, D., Gill, S. and Graham, E. "Evaluation of the adsorptive capacity of peanut hull pellets for heavy metals in solution", Advances in Environmental Research, Vol. 4, Number 1, 2000, pp 19-29.

[30] Kaikake, K., Hoaki, K., Sunada, H., Dhakal, R. P. and Baba, Y. "Removal characteristics of metal ions using degreased coffee beans: Adsorption equilibrium of cadmium (II)", Bioresource technology, Vol. 98, Number 15, pp 2787-2791, 2007.

[31] Qaiser, S., Saleemi, A. R. and Mahmood Ahmad, M. "Heavy metal uptake by agro based waste materials", Electronic Journal of Biotechnology, Vol. 10, Number 3, pp 409-416, 2007.

[32] Babarinde, N. A., Babalola, J. O. and Sanni, R. A. "Biosorption of lead ions from aqueous solution by maize leaf", International Journal of Physical Sciences, Vol. 1, Number 1, pp 23-26, 2006.

[33] Deepa, C. N. and Suresha, S. "Deepa, C. N., \& Suresha, S. (2014). Biosorption of lead (II) from aqueous solution and industrial effluent by using leaves of Araucaria cookii: Application of response surface methodology.", IOSR Journal of Environmental Science, Toxicology and Food Technology (IOSR-JESTFT), Vol. 8, Number 7, pp 6779, 2014

[34] Elibol, M. "Response surface methodological approach for inclusion of per fluorocarbon in actinorhodin fermentation medium", Process Biochemistry, Vol. 38, Number 5, 2002, pp 667-673.

[35] Brasil, J. L., Martins, L. C., Ev, R. R., Dupont, J., Dias, S. L. P., Sales, J. a. A., Airoldi, C. and Lima, É. C. "Factorial design for optimization of flow-injection preconcentration procedure for copper(II) determination in natural waters, using 2aminomethylpyridine grafted silica gel as adsorbent and spectrophotometric detection", International Journal of Environmental Analytical Chemistry, Vol. 85, Number 7, pp 475-491, 2005.

[36] Auta, M. and Hameed, B. "Optimized waste tea activated carbon for adsorption of Methylene Blue and Acid Blue 29 dyes using response surface methodology", Chemical Engineering Journal, Vol. 175, Number 1, pp 233-243, 2011.

[37] Abechi, S. E., Gimba, C. E., Uzairu, A. and Dallatu, Y. A. "Preparation and characterization of activated carbon from palm kernel shell by chemical activation", Res. J. Chem. Sci., Vol. 3, Number 1, pp 54-61, 2013.

[38] Ozcan, A. S., Erdem, B. and Ozcan, A. "Adsorption of Acid Blue 193 from aqueous solutions onto Nabentonite and DTMA-bentonite", J Colloid Interface Sci., Vol. 280, Number 1, pp 44-54, 2004.

[39] Jimoh, T. O., Iyaka, Y. A. and Nubaye, M. M. "Sorption Study of Co (II), Cu(II) and $\mathrm{Pb}$ (II) ions Removal from Aqueous Solution by Adsorption on Flamboyant Flower (Delonix Regia)", American Journal of Chemistry, Vol. 2, Number 3, pp 165-170, 2012.

[40] Sarma, P. J., Kumar, R. and Pakshirajan, K. "Batch and Continuous Removal of Copper and Lead from Aqueous Solution using Cheaply Available Agricultural Waste Materials", Int. J. Environ. Res., Vol. 9, Number 2, pp 635-648, 2015.

[41] Auta, M. and Hameed, B. H. "Preparation of waste tea activated carbon using potassium acetate as an activating agent for adsorption of Acid Blue 25 dye", Chemical Engineering Journal, Vol. 171, Number 2, pp 502-509, 2011.

[42] Araromi, D. O., Alade, A. O., Bello, M. O., Bakare, T., Akinwande, B. A., Jameel, A. T. and Adegbola, S. A. "Optimization of Oil Extraction from Pitanga 
(Eugenia Uniflora L) Leaves Using Simplex Centroid Design (SCD)", Separation Science and Technology, Vol., Number just-accepted, , pp. 2017.

[43] Langmuir, I. "The adsorption of gases on plane surfaces of glass, mica and platinum", Journal of The American Chemical Society, Vol. 40, Number 9, pp 1361-1403, 1918.

[44] Clayton, W. "Capillary and colloid chemistry. By Prof. H. Freundlich. Translated by H. Stafford Hatfield: Methuen and Co., Ltd.", Journal of the Society of Chemical Industry, Vol. 45, Number 44, pp 797-798 1926.

[45] Krishna, R. H. and Swamy, A. "Studies on the removal of $\mathrm{Ni}$ (II) from aqueous solutions using powder of mosambi fruit peelings as a low cost sorbent", Chemical Sciences Journal, Vol. 31, Number 1, pp 1-13, 2011.

[46] Meunier, N., Laroulandie, J., Blais, J. and Tyagi, R. "Cocoa shells for heavy metal removal from acidic solutions", Bioresource Technology, Vol. 90, Number 3, pp 255-263, 2003.

[47] Hasar, H. "Adsorption of nickel (II) from aqueous solution onto activated carbon prepared from almond husk", Journal of hazardous materials, Vol. 97, Number 1, pp 49-57, 2003.

[48] Chakir, A., Bessiere, J., Kacemi, K. E. and Marouf, B. B. "A comparative study of the removal of trivalent chromium from aqueous solutions by bentonite and expanded perlite", Journal of hazardous materials, Vol. 95, Number 1, , pp 29-46,2002.

[49] Akhtar, N., Iqbal, J. and Iqbal, M. "Removal and recovery of nickel (II) from aqueous solution by loofa sponge-immobilized biomass of Chlorella sorokiniana: characterization studies", Journal of hazardous materials, Vol. 108, Number 1, pp 85-94, 2004.

[50] Akhtar, N., Iqbal, M., Zafar, S. I. and Iqbal, J. "Biosorption characteristics of unicellular green alga Chlorella sorokiniana immobilized in loofa sponge for removal of Cr (III)", Journal of Environmental Sciences, Vol. 20, Number 2, pp 231-239, 2008.

[51] Kandah, M. I. and Meunier, J.-L. "Removal of nickel ions from water by multi-walled carbon nanotubes ", Journal of hazardous materials, Vol. 146, Number 1, pp 283-288, 2007.

[52] Demirbaş, E., Kobya, M., Öncel, S. and Şencan, S. "Removal of $\mathrm{Ni}$ (II) from aqueous solution by adsorption onto hazelnut shell activated carbon: equilibrium studies", Bioresource Technology, Vol. 84, Number 3, pp 291-293, 2002.

[53] Lagergren, S. and Svenska, B. K. "On the theory of so-called adsorption of dissolved substances", The Royal Swedish Academy of Sciences Document, Vol. Band 24, Number, pp 1-13. 1898,

[54] Ho, Y. S. and Mckay, G. "Pseudo-second order model for sorption processes", Process biochemistry, Vol. 34, Number 5, pp 451-465, 1999. 